\title{
La minería y la metalurgia nativa en el norte peruano (siglos XVI-XVII) ${ }^{1}$
}

\author{
Susan Elizabeth Ramírez
}

Texas Christian University

Este artículo presenta una visión global de la minería y la metalurgía en el norte de Perú desde tiempos pre-hispánicos tardíos hasta el siglo XVII. Contiene información sobre cómo se manejaban y compartían los recursos, sobre la mano de obra, el procesamiento de los minerales, y los mineros tanto en la costa como en la sierra.

PALABRAS ClaVE: minería, metalurgia, Perú, recursos naturales, mano de obra, mineros.

This article presents an overview of mining and metallurgy in northern Peru from late pre-hispanic times into the seventeenth century. It covers management of and sharing natural resources, labor, processing, and miners on both the coast and highlands.

KEYwords: mining, metallurgy, Peru, resources, labor, miners.

\section{Introducción}

A pesar de la atención que la prensa ha prestado durante las últimas décadas a las excavaciones científicas y al saqueo ilegal de antiguas tumbas de elite que contenían numerosos objetos de oro, plata, cobre y otros metales, durante largo tiempo los etnohistoriadores han descuidado el estudio de la actividad minera en el norte peruano. Una razón fue el sesgo "bullonista" de las primeras oleadas de conquistadores y colonos españoles. Ellos equiparaban los montos de oro y plata (bullion) - ya fueran de un reino, una nación o una persona- con la fuerza y la riqueza y, en consecuencia, dadas sus aspiraciones, no estaban demasiado interesados por los metales más utilitarios como el cobre, el estaño, el plomo y el bronce. El descubrimiento de la mountain of silver (la "montaña de plata" que rendía hasta un marco [8-8.5 onzas cada uno] por libra de mineral de plata), el

1 Unos párrafos de este trabajo fueron publicados en "Ethnohistorical Dimensions of Mining and Metallurgy in Sixteenth Century Northern Peru”, en Craig, Alan, K., y West, Robert C. (eds.): In Quest of Mineral Wealth: Aboriginal and Colonial Mining and Metallurgy in Spanish America, Geoscience and Man XXXIII, diciembre 1994, págs. 93-108. 
Cerro Rico de Potosí, en 1545 desvió rápidamente su atención y los esfuerzos colonizadores hacia el sur. En ese momento el norte - ya fuera sólo la costa lambayecana o la planicie marítima con su hinterland serrano de Cajamarca (e incluso hacia el norte, en territorio cañar) — ofrecía pocas oportunidades semejantes para enriquecerse rápidamente. ${ }^{2}$

Es más, durante las primeras décadas de la invasión y conquista, los españoles asumieron que la prospección, extracción e incluso el trabajo del metal (como se verá luego con el examen de los plateros) eran trabajos propios de los nativos. Hernando de Santillán, un observador español del siglo XVI, sostuvo que "no hay [español] quien sepa de que minas ni como se sacan, porque es cosa que anda entre los indios". Debido a estas actitudes y a la concentrada atención prestada a Potosí y, posteriormente, a Huancavelica y otros ricos lugares (por lo general en la sierra sur), los españoles dejaron pocos registros escritos sobre la minería y la metalurgia en el norte. Los cronistas, algunos de los cuales serán citados más adelante, lo mencionan pero no se detienen a describir las minas y procesos tecnológicos del norte como lo hacen con la zona sur, sobre la cual incluyen extensos, detallados y que, a menudo, complejos informes. Hasta la segunda mitad del siglo XVII, las otras fuentes manuscritas coloniales, como los padrones de tributarios y de censos, los expedientes judiciales, diarios de visitas y otras fuentes administrativas, únicamente se refieren a la minería (si lo hacen) de forma sumaria e incidental. En cuanto las ricas menas del sur se agotaron en su mayor parte y la inundación de los socavones llevó al abandono de varias minas, los recursos minerales del norte atrajeron la sistemática atención burocrática. Luego, los entusiastas oficiales reales hispa-

2 Cobo, Bernabé: Historia del Nuevo Mundo, I, Biblioteca de Autores Españoles, XCI-XCII, Ediciones Atlas, Madrid, 1956, pág. 137; Lohmann Villena, Guillermo: "La minería en el virreinato peruano", La minería hispana e ibero-americana, ponencias del I Coloquio Internacional sobre historia de la minería, I, Congreso Internacional de Minería, Departamento de Publicaciones, León, España, 1970, pág. 644; Shimada, Izumi; Epstein, Stephen, y Craig, Alan K.: "The Metallurgical Process in Ancient North Peru", Archaeology, 1983, pág. 38; Bargalló, Modesto: La minería y la metalurgia en la América española durante la época colonial, Fondo de Cultura Económica, México, 1955, pág. 74. Zárate (citado en Bargalló: La minería..., pág. 74) asegura que los rendimientos eran de 80 marcos por quintal. Para la importancia que el oro y la plata tenían para los conquistadores véase Jara, Álvaro: "Economía minera e historia económica hispanoamericana", Tres ensayos sobre economía minera Hispanoamericana, Universidad de Chile, Centro de Investigaciones de Historia Americana, Santiago de Chile, 1966, pág. 24; Ramírez, Susan: Provincial Patriarchs, Land Tenure and the Economics of Power in Colonial Peru, University of New Mexico Press, Albuquerque, 1986, capítulo 2. El libro de Contreras, Carlos: Los mineros y el Rey. Los Andes del norte: Hualgayoc, 1770-1825, Instituto de Estudios Peruanos, Lima, 1995 y el artículo de González Pujana, Laura: "Minería y trabajo indígena en los Andes, Guamanga y Zaruma", Revista Complutense de Historia de América (Madrid), XVIII, 1992 , págs. 117-131, son dos trabajos que inician la investigación de la industria minera en el norte. 
nos registraron las minas y mineros con fines fiscales. Sus registros, por lo general globales, cada vez más numerosos, se complementan con los casos judiciales y otros informes del tardío siglo XVIII, bajo el estímulo administrativo y fiscal de los reformadores borbones. Pero la minería del siglo XVIII es otra historia. ${ }^{3}$

Aquí se resumirá la información actualmente disponible y algo dispersa sobre los siglos XVI y XVII para brindar un contexto y perspectiva históricos a la información arqueológica y sugerir cómo la minería y la metalurgia se ajustan en la organización socioeconómica de la costa norte. Mis observaciones sobre la metalurgia indígena se basan en los hallazgos prehispánicos reportados en la bibliografía secundaria y en las fuentes manuscritas, que datan de entre 1535 (tres años después de que Francisco Pizarro capturase al inca Atahualpa en Cajamarca) y 1600, aunque la mayoría antecede a la visita toledana de 1572-1573, la cual alteró de manera significativa las costumbres y prácticas de las sociedades nativas de la zona. Se incluyen unos breves comentarios sobre la minería colonial posterior con el fin de indicar los potenciales recursos mineros del norte que, si bien sólo fueron desarrollados tardíamente por los españoles y sus sucesores criollos, tal vez fueron una fuente importante de minerales en tiempos precolombinos. Éstos ciertamente merecen un futuro examen arqueológico.

\section{La metalurgia nativa en el siglo XVI}

\section{Santuarios}

Para los pobladores nativos del norte peruano, al igual que para los de otros lugares, las minas eran objetos o lugares de culto. Cristóbal de Albornoz afirmó que los indios de las huacas de Lucanas, Angaraes, Jauxa y otras provincias del Chinchaysuyu

"Escoxen el más hermoso fruto y le guardan... y desta forma de todos los minerales de oro o plata o azogue que antiquísimamente se han descubierto. Han escogido las

3 Santillán, Hernando de: Relación del origen, descendencia, política y gobierno de los incas, Sanmartí y Ca., Lima, 590, Colección de libros y documentos referentes a la historia del Perú, IX segunda serie, 1927, pág. 104. Para la historia de Hualgayoc en el siglo XVIII, véase Contreras: Los mineros... 


\section{SUSAN ELIZABETH RAMÍREZ}

mas hermosas piedras de los metales y los han guardado y guardan y los mochan llamándolas madres de las tales minas. Y, primero que los vayan a labrar, el día que han de travajar, mochan y beven a la tal piedra llamándola mama de lo que travajan.” ${ }^{4}$

El cronista Bernabé Cobo lo corrobora e informa acerca de que las minas eran consideradas huacas en donde los nativos rezaban y celebraban en su honor con "fiestas en las que los mineros danzaban y bebían chicha durante toda la noche". ${ }^{5}$ Fray Martín de Morúa, un contemporáneo suyo, da mayores detalles:

\footnotetext{
"los solían adorar, e hacer muchas ceremonias particulares de adoración, bebiendo y bailando, teniendolo por aguero; lo mismo solían hacer en las minas que llaman copa, que adoraban y reverenciaban a los metales que llamaban mama, y las piedras de los metales, que llaman corpa, adorábanlas, besándoles y haciéndoles diferentes ceremonias; y a las pepitas de oro en polvo y la plata, y las guayras donde se funde la plata hacían lo mismo..." ${ }^{6}$
}

Está comprobado que los habitantes de la costa norte siguieron esta práctica gracias a los datos proporcionados por un informe administrativo sobre el distrito de Piura, ubicado junto a lo que posteriormente fue el distrito colonial de Lambayeque, que hasta mediados del siglo XVI también incluyó al distrito habitado por los Jayanca. El informe anónimo, ${ }^{7}$ titulado "Relación de la Ciudad de San Miguel de Piura", afirma que los pobladores ofrecían oro y plata a sus huacas y adoratorios, tal como hacían sus análogos del sur. ${ }^{8}$

Si bien el informe no vincula directamente las minas conocidas en el distrito con las huacas y las ofrendas, las evidencias arqueológicas confir-

4 Duviols, Pierre: "Un inédit de Cristóbal de Albornoz: La instrucción para descubrir todas las guacas del Pirú y sus camoyos y haziendas”, Journal de la Société des Américanistes, LVI, 1967, págs. 18, 38. Las afirmaciones de Albornoz comprenden desde Quito hacia el sur. Duviols data el manuscrito hacia finales del siglo XVI.

5 Cobo: Historia...(1890-95), lib. 3, cap. 2, parafraseado por Franch, José Alcina: "La producción y el uso de metales en la América precolombina”, La minería hispana e ibero-americana, ponencias del I Coloquio Internacional sobre historia de la minería, VI Congreso Internacional de Minería, Departamento de Publicaciones, León, España, 1970, pág. 311.

6 Morúa [o Múrua], Fray Martín de: Historia del origen y genealogía real de los reyes incas del Perú, Biblioteca "Missionalia Hispánica", II, Consejo Superior de Investigaciones Científicas, Madrid, 1590/1946, págs. 278-279.

7 Espinoza Soriano, Waldemar: "El Valle de Jayanca y el reino de los Mochica, siglos XV y XVI", Bulletin de l'Institut Français d'Études Andines, IV, núms. 3-4, 1975, pág. 272. Espinoza atribuye el manuscrito a una persona de nombre Céspedes y fecha el documento en 1586.

8 Anónimo: "Relación de la ciudad de San Miguel de Piura", en Urteaga, Horacio H. (ed.): CLDHP, V, segunda serie, Sanmarti y Ca., Lima, 1925, pág. 96. 
man la existencia de dichas prácticas en la región de Lambayeque. En 1984, durante cinco semanas, un equipo, conformado por Izumi Shimada, Alan Craig y el ingeniero José Suárez, halló un depósito de ocho conchas de Spondylus completas, un bien sagrado y preciado entre los nativos precolombinos, en la base del antiguo pozo de una mina en Cerro Meilliso, y concluyó que eran ofrendas rituales similares a las que fueran descritas por Albornoz. Shimada asimismo afirma haber excavado catorce camélidos sacrificados en la Huaca del Pueblo, en Batán Grande, un lugar residencial y metalúrgico relativamente pequeño, de alrededor del año 900 d.C. ${ }^{9}$

Las conchas de spondylus y la ofrendas de camélidos fueron mencionadas por Albornoz al describir un método utilizado para ubicar huacas. Él sostuvo que

\footnotetext{
"en todas las más guacas que están en los cerros y en llanos, tienen al rededor de si unas señales que llaman cachauis, que son señales de los ofrescimientos que a las tales guacas hazían y tienen sus nombres en nombre cada señal del que allí ofresció hijo o carnero[,] de oro o plata o de mollo. Hallarán los ofrescimientos en los tales ceques o cachauis." 10
}

Estos cachauis o ceques, nos dice, podían ayudar a ubicar las huacas y, por extensión, a otras minas.

\section{Minas}

Al parecer, en el norte, los españoles no siguieron este consejo. Si bien las consideraron construcciones que albergaban tesoros ocultos, como las pirámides o los templos, no descubrieron muchas minas. Son pocas las tempranas noticias coloniales de minas en la costa norte. Felipe Guamán Poma de Ayala escribió que Saña, un pequeño curacazgo al sur del valle de Lambayeque, era "pobrécimo de plata y poco oro...". Su información queda confirmada por una copia de la tasa del tributo de los Saña de 1549,

9 Véase Shimada: "Preliminary Report on the 1984 Survey of Ancient Mines in the Lambayeque Region, Peru", Cambridge, 1984, págs. 4 y 7; "Pre-historic Metallurgy and Mining in the Andes: Recent Advances and Future Tasks", en Craig: In Quest..., págs. 53-54; Shimada, Izumi, y Shimada, Melody: "Prehistoric Llama Breeding and Herding on the North Coast of Peru", American Antiquity, 50-51, 1985, págs. 14-15.

10 Duviols: "Un inédit de...", pág. 38. Con respecto al sistema de ceques del Cuzco véase Zuidema, R. Tom: The Ceque System: The Social Organization of the Capital of the Incas, Leiden, 1964; y Bauer, Brian S.: El espacio sagrado de los Incas: el sistema de ceques del Cuzco, Centro de Estudios Regionales Andinos "Bartolomé de las Casas", Cuzco, 1998. 


\section{SUSAN ELIZABETH RAMÍREZ}

hecha por el presidente Pedro de la Gasca, en donde se lee que "no tiene nyngun genero de minas en sus t[ier]rras." Sin embargo, en 1562 hay una referencia a una mina ubicada allí, aunque ignoramos qué mineral era explotado o si en realidad era una mina natural o una "guaca [de] entierro", a veces llamadas "mina" por los españoles. Ese mismo año los españoles reportaron depósitos de oro y plata en el valle de Túcume o La Leche, unos cuantos kilómetros al norte. La antes mencionada "relación" temprana que describe a Piura también transmite que había minas de oro y plata a la vista de la ciudad, pero que no se las explotaba porque no eran rentables. ${ }^{11}$

Las modernas prospecciones del valle de Saña y otros valles han mostrado que la región tiene numerosas minas prehispánicas y coloniales, la mayoría de cobre. Más exploraciones descubrieron amplias evidencias de excavaciones indígenas. Heather Lechtman halló, en la prospección que hiciera de la costa norte, por lo menos tres yacimientos mineros prehispánicos de cobre (aunque posiblemente existieron más), sin contar los que fueron explotados en tiempos coloniales y después, en donde los restos de la minería y el procesamiento precolombinos podrían haber sido destruidos. ${ }^{12}$ Ella concluye

"que la costa norte peruana es una zona repleta de minerales de cobre, en particular los óxidos y carbonatos que son tan fáciles de fundir... Todas las evidencias indican que dichos minerales fueron explotados sistemáticamente por los españoles, y estoy segura que también lo fueron mucho antes por los pobladores andinos." ${ }^{13}$

Lechtman también menciona a Chilete (Chilequete en la temprana [1540] documentación colonial, a 1000 metros de altura y a un día de cami-

11 Ramírez: The World Upside Down: Cross-cultural Contact and Conflict in Sixteenth Century Peru, Stanford University Press, Stanford, 1996, cap. 5; Anónimo: "Breve relación de la ciudad de Truxillo y de las Villas de Miraflores, La Parrilla, Arnedo y Cañete", en Urteaga, Horacio (ed.): Colección de libros y documentos referentes a la historia del Perú (CLDHP), V, segunda serie, Sanmarti y Ca., Lima, 1925, pág. 129; Anónimo: “Relación...”, pág. 79; Archivo General de las Indias (AGI), Justicia 458, f. 1468; Justicia 1065, 5-VIII-1535, esta última fuente cortesía de John V. Murra; Guamán Poma de Ayala, Felipe: Nueva corónica y buen gobierno, 3 vols., Siglo XXI, México, 1613/1980, folio (f.) 1020 [1028]; Biblioteca de la Real Academia de Historia (BAH), 9-4664, f. 23v; Archivo Regional de Trujillo (ART), López de Córdova, 24-IX-1562; Mata, 1-VII-1562. Es posible que los nativos informaran a la Gasca de que no había minas en sus tierras para escapar de la obligación de trabajarlas.

12 Lechtman, Heather: "A Metallurgical Site Survey in the Peruvian Andes", Journal of Field Archaeology, III, 1976, págs. 9-16; Shimada: "Preliminary Report..."; y "The Metallurgical Process...”. Véase también su nota 23 y la página 13 para la costa más próxima a Trujillo.

13 Lechtman: "A Metallurgical Site Survey...”, pág. 15. Una prospección alemana de la zona es más pesimista. 
no de la costa, en la orilla norte del valle del Jequetepeque) como una fuente costeña ${ }^{14}$ precolombina de plata, aunque en 1540 los españoles consideraron que el lugar formaba parte de Cajamarca y era, por lo tanto, un dominio serrano.

La prospección arqueológica mencionada muestra la presencia de por lo menos media docena de minas. La de Cerro Meilliso es rica en plata. La arquitectura de mampostería estandarizada y las impresionantes terrazas argumentan en favor de la importancia particular de esta mina, tal vez precisamente debida a sus minerales de plata. La mayor parte de los yacimientos restantes son fuentes de cobre.

Tanto los registros arqueológicos como los virreinales indican, en cambio, que la sierra norte era más rica en recursos minerales que la costa. Se sabía que partes de la región general de Cajamarca tenían numerosos depósitos minerales, en especial de plata. Como ya se mencionó, Chilete muy probablemente fue un importante centro minero de plata ya en $1540 \mathrm{e}$ incluso antes de que lo descubrieran y explotaran los españoles. ${ }^{15}$ También, se extraía plata y oro en la zona serrana de Conchucos. De hecho, ya en 1535 Pizarro dio permiso a su teniente en el Valle de Trujillo, el capitán Martín de Estete, para que "rescatar[a]" con los caciques de Chimo y Conchuco, sus subordinados y súbditos, el oro y plata que tuvieran en su posesión. Hernando Pizarro, el hermano de Francisco, menciona a Cajamarca en 1541 como una importante zona potencialmente minera. El licenciado Vaca de Castro asimismo incluyó a Cajamarca y Conchucos en las observaciones que hiciera al rey, señalando que "el provecho destas tales minas esta en correr bien el metal y aber leña que avnque rresponda a poco por quintal es grande el prouecho". ${ }^{16}$

El distrito de Huamachuco era una zona rica en minerales, así como la zona cerca de Chota, en donde los nativos de Conduzmarca y Bambamarca trabajaban las minas ${ }^{17}$ en 1560 . Luego, en su visita a la zona norte, el arzobispo don Toribio Alfonso de Mogrovejo encontró cuatro familias nativas con dieciséis miembros trabajando minas en la década de metros.

14 La definición que Lechtman da de la costa abarca desde el nivel del mar hasta los 2.000

15 Málaga Santolalla, Fermín: "Importancia minera de la provincia de Cajamarca", Boletín del Cuerpo de Ingenieros Mineros del Perú, 31, 1905, pág. 21. Reporta erróneamente que los depósitos de menas de Chilete fueron descubiertos por los portugueses a mediados del siglo XVII.

16 Bargalló: La minería ..., págs. 38 y 76; AGI, Justicia 415, f. 194v; Justicia 1063, n. ${ }^{\circ}$ 3, 1570, f. 5v; Justicia 1065, f. 1535, cortesía de J.V. Murra; Patronato 90A, n. ${ }^{\circ} 1$, R. 25, 1; P 185, r. 21 , f. 1.

17 Se ignora cuál era el mineral aludido. 
1590. Otra mina que también visitó en la misma época, cerca de Celendín, era trabajada por esclavos negros y un número indeterminado de campesinos de la localidad. Sólo los pobladores nativos de Guambos, la zona que incluye las cabeceras del río Lambayeque o Chancay, tierra en dirección al este de Íllimo, negaron categórica y repetidamente tener acceso a mina alguna: "los nat[urale]s de guambos son pobres. No tienen minas". ${ }^{18}$

Tierra adentro se sabía que había plata en el territorio cañar, en lo que hoy es Ecuador. También se informó acerca de que los Chachapoyas (más al interior todavía) tenían depósitos ricos de oro y plata ya en 1538, por lo que se puede afirmar, casi con toda seguridad, que se desarrollaban actividades mineras precolombinas. Las fuentes son curiosamente silenciosas con respecto a las ricas zonas mineras de oro de Pataz y los depósitos de plata de Hualgayoc, cerca de Chota, ${ }^{19}$ que fueron descubiertos en siglos posteriores. Además, rara vez se mencionan los depósitos de cobre que, según los arqueólogos, eran de suma importancia para la economía nativa. ${ }^{20}$

\section{Actividades mineras}

Sin embargo, los habitantes prehispánicos de la región ciertamente sabían dónde estaban las minas. Craig sostiene que las fuentes de minerales podrían haber sido localizadas encontrando float mineralizado en los lechos secos de los ríos y siguiendo el rastro corriente arriba, o usando plantas indicadoras. En consecuencia, una avanzada industria metalúrgica había florecido en la costa norte durante siglos, bajo el mando de las autoridades locales. Cobo afirma que "sacábanlo [al cobre] antiguamente los indios en mucha cantidad, a cuya causa se ven hoy muchas minas labradas de tiempo antiguo". Más tarde, con la conquista de estas poblaciones, los incas tal vez tomaron medidas para expandir las dimensiones de la indus-

18 Loredo, Rafael: Los repartos: s. p. i., Lima, 1958, pág. 255; AGI, Justicia 457, f. 744; Justicia 461, f. 1443v-44; Mogrovejo, Don Toribio Alfonso de: "Diario de la segunda visita pastoral que hizo de su arquidiócesis el ilustrísimo señor don Toribio Alfonso de Mogrovejo, arzobispo de Los Reyes", Revista del Archivo Nacional del Perú, I, 1920, págs. 67, 93. La Memoria, publicada por Loredo (Los repartos..., pág. 256), afirma que podrían haber estado trabajando en las minas en 1549.

19 Salvo que éstos sean los depósitos que los nativos de Conduzmarca y Bambamarca estaban trabajando en la década de 1560

20 Bargalló: La minería..., pág. 38; Romero, Carlos A.: "Fundación de las ciudades de Chachapoyas y Celendín", Revista histórica, XI, Entregas I-2, 1937, págs. 185, 187; Loredo: Los repartos..., págs. 259-264. 
tria. Guamán Poma de Ayala sugiere que Cápac Yupanqui, y presumiblemente también sus sucesores, iniciaban la búsqueda sistemática de recursos minerales una vez asegurada la lealtad de los pueblos recién contactados. Él escribió que "Capa Yupanqui Ynga mandó descubrir todas las minas de oro y plata, azogue, limpi, y chima, cobre, estaño, y de todas las colores". Esta búsqueda organizada de recursos minerales indica cuán importantes eran cultural y económicamente. ${ }^{21}$

\section{Proveimiento}

Las fuentes hispanas afirman que todas las minas pertenecían al soberano inca por derecho de conquista, y que eran explotadas en su beneficio. ${ }^{22}$ En palabras de un autor del siglo XVI, "en las prouincias donde avia minas echavan a sacallo cierta cantidad de indios y todo lo que se hallaua se enbiava cada un año al ynga y tanbien en esto avia q[uen]ta...”. Un manuscrito del Museo Británico, titulado "Horden que el Inga tubo en la governacion del Piru", reitera que "Donde auia minas de joro y plata Andaban yndios En ellas Sacando para el ynga, y los que hacian esto no daban otro tributo ni Seruiçio". ${ }^{23}$

El oro y la plata estaban reservados para el uso exclusivo del inca y los señores que le estaban sujetos..$^{24}$ Los metales eran trabajados en diversas formas ornamentales y artículos funerarios. La relación de 1561 afirma que "si era oro o plata todo lo hazia vassos y ornatos de las casas de su rreligion y enterravanse con ello...". ${ }^{25}$ Sin embargo, los artículos de cobre y

21 Craig, Alan K.: "Origins and Development of Andean Mining", inédito, 1994; Cobo: Historia..., I, pág. 151; Guamán Poma de Ayala: Nueva corónica..., f. 101.

22 Podría ser una creencia íntegramente hispana que fue atribuida a los nativos.

23 Lorente citado en Carranza, Fortunato: "La metalurgia del Perú incaico", Boletín de la Sociedad Geográfica (de Lima), XL, núms. 1-2, 1923, pág. 53; Rodríguez-Rivas, Daniel Alonso: "La legislación minera hispano-colonial", en La minería hispana e ibero-americana, ponencias del I Coloquio Internacional sobre historia de la Minería, Congreso Internacional de Minería, Departamento de Publicaciones, León, España, 1970, pág. 659; AGI, Patronato188, R. 22, 1561, f. 5v; British Museum, Add. 13992, f. 414

24 Franch ("La producción...", pág. 310) cree que aparentemente no había ninguna forma de impedir del todo que la gente del común consiguiera algunas menas para su propio uso; véase también Lohmann Villena: "La minería...”, pág. 659; Espinoza Soriano: "El Valle de Jayanca...", pág. 275.

25 Los metales también fueron usados con estos fines (y otros) en el norte preincaico. Véase Shimada: "Perception, Procurement and management of Resources: Archaeological Perspective", en Masuda, Shozo; Shimada, Izumi, y Morris, Craig (eds.): Andean Ecology and Civilization, University of Toyko Press, Tokyo, 1985, págs. 367-368. 
bronce (como anzuelos y cuchillos) estaban a disposición de la gente del común. ${ }^{26}$

En la práctica, los curacas locales, que organizaban y supervisaban la mano de obra, controlaban las minas al igual que otros recursos naturales y producción. Un informe inédito, redactado en 1561, relata cómo el gobernador provincial solicitaba mineros "si el governador mandava que mill indios desta provinçia fuessen este verano a sacar oro para el inga davanlos las parçialidades por su q[uen]ta y rrason cada uno según los indios que tenia". Si bien este pasaje tal vez evoque imágenes de una hueste de mineros que partían a las minas como un cuerpo, como una gran centralización, las fuentes arqueológicas y las manuscritas de nivel local indican lo contrario. En realidad, es probable que los señores locales supervisaran la adquisición y extracción misma de los minerales. En general, las fuentes históricas sugieren que los curacas asignaban gente del común ("mineros") para que trabajaran en los pozos y minas poco profundos de donde se extraía la mayor parte de los minerales (salvo el oro). ${ }^{27}$ Los comuneros trabajaban como mineros de forma estacional y temporal, tal vez como parte de su mita (el tributo en servicios laborales rotatorios). El número de trabajadores asignados a estas tareas era pequeño. Santillán afirma que "en la provincia que tenía minas o las alcanzaba cerca, pedia el inga para sacar oro dellas de cient Indios uno". Dada la pequeña escala de las actividades mineras prehispánicas en el norte, es probable que el trabajo fuera individual o bien realizado por pequeños grupos..$^{28}$

Los medios exactos con los que se accedía a los recursos minerales sigue siendo materia de debate. Hay evidencias para respaldar varios mecanismos distintos. Uno de ellos era la explotación directa de los recursos por un curaca y su gente. Tanto las evidencias arqueológicas como las históricas respaldan esta explicación. Los informes de prospecciones geológicas recientes señalan la presencia tanto de los minerales de cobre como de las portadoras de arsénico, necesarias para producir los artefactos ceremonia-

26 AGI, Patronato 188, R. 22, 1561, f. 11; Lechtman: "A Metallurgical Site Survey...”, pág. 14; Lechtman: "Issues in Andean Metallurgy", en Benson, Elizabeth P. (ed.): Pre-columbian Metallurgy of South America, Dumbarton Oaks Research Library and Collections ,Washington, D.C., 1979, pág. 25.

27 El oro aparentemente se obtenía lavando en los arroyos. Cobo (Historia..., I, pág. 140) afirma que en la época prehispánica se le conseguía en placeres. Los indios no sabían cómo extraer oro de la roca.

28 AGI, Patronato 188, R. 22, f. 10; Shimada: "Preliminary Report...”, pág. 4; "Procurement and management of Resources..."; "Pre-historic Metallurgy and Mining...", págs. 49, 54; Carranza: "La metalurgia...", pág. 53; Rodríguez-Rivas: "La legislación...", pág. 659; BAH, A92, f. 17; AGI, Patronato 188, R. 22, 1561, f. 10; Santillán: Relación..., pág. 39. 
les y utilitarios que los arqueólogos han encontrado, y por los que la región fue adquiriendo fama. ${ }^{29}$

Pero en ciertos casos los minerales necesarios tal vez no estaban disponibles a corta distancia. En estas condiciones, los curacas de la costa habrían tenido dos opciones: una era la explotación directa efectuada por sus propios súbditos, a quienes se enviaba y estacionaba en áreas relativamente distantes para que extrajeran las menas. Martín de Morúa, el cronista del tardío siglo XVI, señala que los "indios mitimaes para las minas de oro y plata y demás metal y minas de colores... no trabajaban en ellas sino era cuando el Inga lo mandaba; residian de ordinario en las minas, sustentabanse de las chácaras". Otros mitimaes (colonos) eran establecidos en zonas lejanas para que proporcionaran a su comunidad recursos tales como la coca, que a veces no estaban a la mano. ${ }^{30}$

En los escritos de diversos cronistas y en los informes de otros contemporáneos hay un indicio de que ésta era una práctica común; ellos afirman que ciertas zonas mineras eran multiétnicas, en el sentido de que los nativos de varias etnías trabajaban los depósitos de manera simultánea bajo la dirección de sus distintos curacas. Pedro Sancho de la Hoz comenta respecto del principal centro minero en Guarnacabo (en el Collao):

"La[s] gentes que aquí sacan oro podrán ser hasta cincuenta entre hombres y mujeres y éstos son de toda esta tierra, de un cacique veinte y de otra cincuenta y de otra treinta; y de otra más o menos, según que tienen, y lo sacan para el señor principal." ${ }^{11}$

Santillán alude al mismo patrón en Zamora (en el actual Ecuador): "En Zamora, que es un poco mas grueso el trato de oro, mueren los que de otras partes allí vienen...". ${ }^{32}$ Los trabajadores viajaban desde zonas tan dis-

29 Merkel, J. F., Shimada, I., Swann, C.P., y Doonan, R.: "Pre-Hispanic Copper Alloy Production at Batan Grande", en Scott, David A., y Meyers, Pierter (eds.): Archaeometry of PreColumbian Sites and Artifacts, Getty Conservation Institute, Los Ángeles, 1994, págs. 199-228; Shimada: "Preliminary Report..."; "Procurement and management of Resources...", págs. 372-377; "Pre-historic Metallurgy and Mining..."; Lechtman: "Technologies of Power: The Andean Case", en Henderson, John S., y Netherly, Patricia J. (eds.): Configurations of Power: Holistic Anthropology in Theory and Practice, Cornell University Press, Ithaca, 1993, págs. 244-280; Shimada: comunicación personal, 22-III-1985.

30 Morúa: Historia ..., pág. 332; Spalding, Karen: "La red desintegrante” en De indio a campesino, Instituto de Estudios Peruanos, Lima, 1974, pág. 98.

31 Sancho de la Hoz, Pedro: "Relación para S.M. de lo sucedido en la conquista..." en Urteaga, Horacio H. (ed.): Los cronistas de la conquista. Biblioteca de cultura peruana, primera serie, 2, Desclée de Brouwer, París, 1938, pág. 181.

32 Santillán: Relación..., pág. 106. 
tantes como el Darién (Panamá) y Lima para trabajar, y no sólo para intercambiar [trade]. Citando un manuscrito temprano de la zona de Huánuco, Rolando Mellafe también señala el uso multiétnico de un área minera:

"en este asiento de Chuquibamba habia puesto en tiempo del Ynga yndios curicamayocs que son yndios para sacar oro del poço que esta en esta puente de diferentes naciones y estaban poblados y avencindados en una y otra parte del rio." ${ }^{3}$

Un número cada vez mayor de fuentes primarias, entre ellas la visita de Jayanca de 1540, la merced de encomienda de Túcume de 1541 y numerosas otras que datan de antes de las reducciones emprendidas por el Dr. Gregorio González de Cuenca, oidor de la Real Audiencia y visitador, en 1566, así como por el virrey Francisco de Toledo en 1572-1573, indican que era usual que los señores costeños tuvieran súbditos en la sierra. El patrón de asentamiento original de los súbditos de un curaca principal era el de estancias pequeñas ampliamente dispersas que rodeaban al tambo o centro religioso y administrativo y a las que los españoles, a veces, llamaban mitimaes; algunas estaban dispersas desde el litoral hasta la sierra de Cajamarca. Un cacique principal de la costa aseguró en 1566 que él tenía "sus pueblos en distrito de mas de treinta leguas desde la mar hasta caxamarca". ${ }^{34}$

Algunos grupos costeños que vivían en la sierra todavía seguían sirviendo a su señor en la década de 1560, como aquellos olleros naturales de Jayanca pero que vivían en la sierra entre los Guambos y las nueve aldeas de los súbditos del curaca de Saña ${ }^{35}$ que vivian en la sierra entre los Cajamarca. A pesar de que existen numerosas referencias a los grupos periféricos de Cajamarca, no sabemos con exactitud cómo y dónde vivían. Sólo conocemos cinco de los nueve poblados habitados por los llamados mitimaes de Saña en Cajamarca; probablemente no eran mineros porque a fina-

33 Bargalló: La minería..., pág. 72; Mellafe, Rolando: "La significación histórica de los puentes en el virreinato peruano del siglo XVI", Historia y cultura, I, 1, Lima, 1965, pág. 87.

34 Espinoza Soriano: "El Valle de Jayanca"...; ART, Corregimiento Ordinario (CoO), 13-VII1570, f. 96v-99; Ramírez: "Chérrepe en 1572: Un análisis de la visita general del virrey Francisco Toledo", Historia y cultura, XI, Lima, 1979, págs. 56-95; Loredo: Los repartos..., págs. 271-273; AGI, Justicia 457, f. 1013; Justicia 458, f. 1829v-30v; Patronato 189, R. 11, 1566; Audiencia de Lima (AL) 92

35 No me refiero a los grupos de costeños en la sierra de Cajamarca, que se sabe fueron colocados allí para que sirvieran a los incas como alfareros o para manejar los tambos (Espinoza Soriano: "Los mitmas yungas de Collique en Cajamarca, siglos XV-XVII", Revista del Museo Nacional (Lima), XXXVI, 1969-70, págs. 9-57; AGI, Justicia 1063,1570, n. ${ }^{\circ}$ 5; véase infra). 
les de la década de 1560 sostenían no tener plata para pagar el tributo, por lo cual se presume entregarían ropa a su curaca. ${ }^{36}$

En el norte, un lugar lógico de interacción entre costa y sierra están las minas de Chilete, ubicadas a 1000 metros por encima del nivel del mar tierra adentro, siguiendo al río Jequetepeque, entre Pacasmayo y Cajamarca. Se sabe que Chilete es una fuente de minerales arsenicales necesarios para fabricar el bronce o la aleación de cobre que es común en los artefactos encontrados por arqueólogos en la costa. Un documento afirma que por lo menos dos grupos de nativos trabajaban allí en la década de 1540 bajo el mando de distintos señores. Por desgracia, la fuente manuscrita no identifica a los grupos por su origen, ni tampoco les denomina mitimaes. Otro manuscrito informa de que en esa época, algunos de los mineros de Chilete eran pobladores de la costa que no trabajaban directamente para sus propios señores. Citando fuentes coloniales tempranas, José Antonio del Busto afirma que los curacas de Cajamarca hacían que los nativos de la costa explotaran ciertas minas de la sierra que se encontraban bajo su jurisdicción o control. De esta manera, sugiere que sus propios señores costeños no manejaban dichos recursos minerales. Por lo tanto, las evidencias de una explotación directa de estos recursos en la sierra por parte de colonos costeños siguen siendo circunstanciales. ${ }^{37}$

El problema es, entonces, establecer los mecanismos que daban acceso al grupo (a los grupos) foráneo(s). Una posibilidad es que los señores de la sierra permitieran a los trabajadores costeños compartir los depósitos a cambio de parte del producto de su trabajo; a saber, las menas [ore $].^{38}$ Por lo tanto, los curacas de Cajamarca que, al parecer, controlaban Chilete y otros lugares, y otros señores que administraban los recursos de minerales exóticos (por ejemplo, oro en el área ocupada por los Chachapoyas) probablemente daban la bienvenida a los reclutas externos, pues como condición para compartir el recurso recibían parte de la producción. El acceso sería una señal de la generosidad del señor, que asociada a los banquetes y la bebida, que probablemente precedían al inicio de las obras, también mejo-

36 AGI, Justicia 457, f. 1008; Justicia 460, f. 377v, 385; Justicia 461, f. 1256, 12575v, 1396, 1527v; Justicia 462, f. 1860v, 1875; y AL 200.

37 Bargalló: La minería ..., pág. 41; Málaga Santolalla: "Importancia minera...”, págs. 24-25; AGI, Justicia 415; AL 568, citado en Busto, José Antonio del: "El capitán Melchor Verdugo, Encomendero de Cajamarca", Revista histórica, XXIV, 1959, págs. 369 y 386.

38 Para un examen de los recursos compartidos a cambio de trabajo, sobre todo tierra y agua, véase Ramírez: "Social Frontiers and the Territorial Base of Curacazgos", en Masuda: Andean Ecology..., págs. 423-444. 
raba la reputación y el prestigio del anfitrión y sus súbditos. Semejante generosidad era un aliciente para que los trabajadores extrajeran más metal. ${ }^{39}$

Otra posibilidad es que los minerales en bruto, incluso artefactos de metal terminados, hayan sido intercambiados por ciertos productos de la costa, tales como las telas de algodón, el ají o el maíz. Las leyendas y la documentación virreinal sobrevivientes describen cómo los señores costeños pagaban con sal, ají y ropa a sus pares de la sierra a cambio del derecho al agua. Shimada también comenta que los batangrandinos antes de 1950 llevaban algodón, pescado salado y seco y otros productos en burro hasta las cabeceras de los ríos La Leche y Lambayeque, para trocarlos por productos de la sierra. ${ }^{40}$

La documentación de la visita y la residencia del Dr. Cuenca también menciona a los "mercaderes". He sostenido en otro lugar que éstos no eran comerciantes en un sentido comercial y capitalista, como el grupo especializado de comerciantes de México - los pochteca-, que intercambiaban para obtener ganancias personales y enriquecerse, como sugiere la obra pionera de María Rostworowski. Sostengo, más bien, que eran criados [retainers] del señor, especialistas en el intercambio, dedicados al transporte e intercambio de bienes bajo la supervisión directa del curaca o del estado inca. Sea cual fuere su identidad verdadera, su existencia sugiere la posibilidad del intercambio. ${ }^{41}$

39 Ramírez: "Social Frontiers..."; Santillán: Relación..., pág. 88; Cieza de León, Pedro de: Travels of Pedro Cieza de León, Hakluyt Society, Londres, 1864, pág. 229; para la hospitalidad véase Poma de Ayala: Nueva corónica..., f. 980 [912-13]; y f. 136.

40 Archivo Castillo Muro Sime (ACMS), 1654-1765, f. 7-7v; y mi examen en Ramírez: "Social Frontiers...", pág. 434 y nota 20; Shimada: "Behind the Golden Mask: The Research Problems and Preliminary Results of the Batan Grande-La Leche Valley Archaeological Project", inédito, Princeton, Nueva Jersey, 1979, págs. 29-30.

41 Rostworowski de Díez Canseco, María: "Mercaderes del Valle de Chincha en la época prehispánica: Un documento y unos comentarios", Etnia y sociedad, Instituto de Estudios Peruanos, Lima, 1977, págs. 97-140; Ramírez: "Retainers of the Lords or Merchants: A Case of Mistaken Identity?", en Millones, Luis, y Tomoeda, Hiroyasu (eds.): El hombre y su ambiente en los Andes Centrales, Senri Ethnological Studies, 10, Kyoto, Japan, 1982, págs. 123-136; y "Social Frontiers..."; véase también Ramírez: "Un mercader es un pescador: Reflexiones sobre las relaciones económicas y los múltiples roles de los indios americanos en el Perú del siglo XVI", en Varón Gabai, Rafael, y Flores Espinoza, Javier (eds.): Arqueología, antropología e historia en los Andes. Homenaje a Maria Rostworowski, Instituto de Estudios Peruanos, Lima, 1997, págs. 729-736 y "Rich Man, Poor Man, Beggar Man or Chief: Two Views of the Concept of Wealth in Sixteenth Century Peru", en Kellogg, Susan y Restall, Matthew (eds.): Dead Giveaways: Indigenous Testaments of Colonial Spanish America, University of Utah Press, Salt Lake City, 1998, págs. 215-248. 
El informe de 1561 ya citado indica que el intercambio inter-comunal era practicado en la costa antes de su conquista por los incas. El manuscrito dice así:

\begin{abstract}
"en t[iem]po de los ingas no avia estimaçión en ning[un]a cosa a dineros porque no se comprava comida con oro ni con plata dado casso que alg[un]as comunidades de los llanos Rescatavan oro y plata con los bastimientos que llevavan a la sierra pero en esto concluyen cassi todos los viejos que esto fue antes quel inga los conquistasse por que despues avia pocas contractaçiones desta manera y las que avia eran permutaçiones como ropa de algodon por de lana o pescado por otras comidas lo primero se hazia con los prinçipales por que la gente comun solo rescatava comida por comida $\mathrm{y}$ en poca cantidad en lo qual tanbien ay diferentes costumbres en unas partes que en otras." ${ }^{42}$
\end{abstract}

Esta cita clave afirma que antes de que los incas conquistasen a los chimúes de la costa, los alimentos y la ropa (los "bastimientos") eran intercambiados respectivamente por minerales por los pueblos de esta zona geográfica y los de la sierra. Después de que los incas tomaran el control, los intercambios disminuyeron en número e importancia, coincidiendo tal vez con la notoria reubicación de pueblos que siguió a la expansión incaica. La escala de los intercambios tanto antes como después de la conquista inca argumenta a favor de la administración estatal. Esta cita y su interpretación debieran asimismo respaldar la hipótesis de que los "naipes" (objetos de metal en forma de hacha) encontrados en contextos funerarios, en lo que hoy es la costa sur de Ecuador y el norte de Perú, fueron tal vez un medio de intercambio estandarizado en la época preinca. ${ }^{43}$

En suma, las evidencias no aclaran la ubicación exacta de los recursos minerales necesarios para la metalurgia costera, pero sí ayudan a resolver el debate en torno al (a los) mecanismo(s) con que se les conseguía. Si los minerales estaban disponibles localmente, la explotación directa probablemente habría sido la norma. De lo contrario, el intercambio de productos entre señores habría sido un mecanismo que, según nuestros conocimientos actuales, antecedió en la costa al dominio inca. Esto podría explicar la supervivencia de especialistas en el intercambio en las etnias incorporadas por un breve lapso al imperio inca. Luego, el intercambio directo fue reemplazado con la explotación directa (una explicación problemática) y/o el

42 AGI, Patronato 188, R. 22, 1561, f. 8v-9.

43 Shimada: "Procurement and management of Resources...", págs. 375-376. 
compartir los recursos trabajados con colonos o mitayos. Las opciones están resumidas en la siguiente figura. ${ }^{44}$

\section{FIGURA I}

FORMAS DE ADQUISICIÓN DEL MINERAL POR LOS SEÑORES COSTEÑOS, 1530

\begin{tabular}{|l|l|l|}
\hline & Directa & Indirecta \\
\hline Bajo su dominio & Explotación directa & $\begin{array}{l}\text { Recursos compartidos } \\
\text { (con ayuda de forasteros) }\end{array}$ \\
\hline Sin dominio & $\begin{array}{l}\text { Colonos bajo su mandato } \\
\text { (evidencia circunstancial) }\end{array}$ & $\begin{array}{l}\text { - Recursos compartidos } \\
\text { (Chilete, Zamora) } \\
\text {-Trueque (pre-incaico) }\end{array}$ \\
\hline
\end{tabular}

Procesamiento: Los minerales, hayan sido extraídos o conseguidos de otro modo por estos trabajadores, al parecer, eran transportados en caravanas de llamas a un centro para su procesamiento. ${ }^{45}$ En el siglo XVI, varios de los señores de la costa poseían pequeños rebaños; por ejemplo, don Diego Mocchumi, principal de Túcume tenía nueve de ellos. Los habitantes de Moro y Tecap(a) también tenían llamas en 1582. En los caminos y pistas $^{46}$ entre la costa (y sobre todo entre la comunidad de Collique) y Cajamarca había "corrales hechos de tierra y de piedra o de tierra donde dizen que antiguamente tenian en los d[ich]os corrales los carneros o ovejas de la tierra de guaynacava". ${ }^{47}$

44 Shimada: "Procurement and management of Resources...", págs. 357-358; Salomon, Frank: "Ethnic Lords of Quito in the Age of the Incas: The Political Economy of North-Andean Chiefdoms", Tesis de Ph.D., Universidad de Cornell, Ithaca, Nueva York, 1978.

45 En la costa las llamas también eran necesarias para las ceremonias mortuorias (Poma de Ayala: Nueva corónica..., f. 297 [299]); Ramírez: To Feed and Be Fed: The Cosmological Bases of Authority and Identity in the Andes, Stanford University Press, Stanford, 2005, capítulos 3-4.

46 Con respecto a los caminos entre costa y sierra véase también Archivo Nacional del Perú, Real Audiencia (RA), 1. 194, 1675, f. 131v; Archivo Notarial Carlos Rivadeneira (ANCR), Cossío, $14-$ VIII-1752; ART, Intendencia Compulsa (IC), 16-II-1785, f. 289v.

47 Shimada, Izumi, y Shimada, Melody: "Prehistoric Llama Breeding...”, pág. 20; ART, Corregimiento Residencia (CoR), 30-VI-1576; ART, CoO, 11-VIII-1582; AGI, Justicia 461, f. 856v. 
Una vez en el centro de procesamiento, los minerales eran fundidos y los metales resultantes eran convertidos en artefactos por pequeños grupos de trabajadores especializados. Los descubrimientos arqueológicos y las obras de los cronistas tempranos sugieren que se molían con martillos de piedra y/o batanes (piedras de moler andinas), y luego fundían en pequeños hornos de arcilla que usaban la energía eólica que a veces circulaba por tubos para obtener una llama intensa y la temperatura necesaria para fundir el mineral. ${ }^{48}$ Morúa describe el proceso practicado en la sierra sur, lo que nos da cierta idea de la probable tradición norteña:

\begin{abstract}
"guayréanse solamente los metales muy ricos, por si solos, si son plomizos; y si secos, con alguna liga que los haga luego derretirse y correr ... Para derretirlos los ponen en los collados y laderas, donde con mas fuerza soplan los vientos en unos braseros grandes de barro que llaman guayras, con carbón encendido y el metal dentro; y como se va derritiendo, va consumiendo el fuego la escoria y purificando la plata. Toda la que sacaban los indios... antiguamente era por este modo de fundición, por que no supieron otro beneficio; y a esta causa no aprovechaban sino los metales muy ricos." 49
\end{abstract}

En la costa, en lugar de colocar hornos de arcilla en las laderas para aprovechar el viento, parece ser que era más común elevar la temperatura interna usando "tubos para soplar" (blow tubes). Garcilaso de la Vega describe esta práctica (hacia 1609):

"Fundían a poder de soplos con unos cañutos de cobre, largos de media braza, más o menos, como era la fundición, grande o chica. (...) Juntavanse ocho, diez, y doce, como era menester para la fundición: andaban al derredor del fuego, soplando con los canutos, y oy se están en lo mismo que no han querido mudar costumbre." ${ }_{50}$

\title{
Mineros
}

La subsistencia de los orfebres, llamados "plateros" por los españoles, así como las materias primas necesarias para el procesamiento eran propor-

48 Para una descripción más detallada de este proceso, véase Shimada, Izumi; Epstein, Stephen, y Craig, Alan K.: "The Metallurgical Process...".

49 Morúa: Historia..., págs. 278-279.

50 Citado en Bargalló: La minería..., pág. 40. Véase también la descripción en Contreras: "Técnicas indígenas y españolas en el beneficio de la plata en el Perú colonial (Siglos XVI-XVII)" en Pino Díaz, Fermín del (coord.): Dos mundos, dos culturas: O de la historia (natural y moral) entre España y el Perú, Vervuert, Madrid, 2004, pags. 39-58. 
cionadas por los curacas. Pequeños grupos de estos plateros ${ }^{51}$ trabajaban en las cortes de los señores de Lambayeque, Collique y Jayanca y recibían de ellos comida, ropa y otros artículos necesarios para subsistir. ${ }^{52}$ Según Morúa, también estaban exentos de otros servicios en tributo. ${ }^{53}$

La madera o el carbón necesarios para alimentar el fuego también eran proporcionados en la cantidad necesaria por los curacas, para quienes trabajaban los orfebres. Era una antigua tradición que cada señor recibiera de sus súbditos trabajo para su casa. Además de llevar agua, una de sus obligaciones era cortar y reunir leña, y transportarla al centro administrativo, donde probablemente era almacenada y usada por los cocineros, los fundidores y los orfebres según la necesitaran. ${ }^{54}$

Los plateros eran tan afamados por su habilidad técnica que el inca envió un grupo de ellos a que viviera en Cuzco; fabricaban diversos utensilios de cobre y bronce, y adornos de oro y plata - como agujas, pinzas y anzuelos- para fines decorativos, y trompetas de cobre, coronas de plata ("coronas de plata baja de baile de yndios") y vasijas para beber ("cocos de plata yunga") lo suficientemente grandes como para dos personas, utilizadas en celebraciones y festividades rituales hasta el siglo XVII. ${ }^{55}$

51 La mayoría de los grupos de artesanos eran demasiado pequeños. Los nativos que hacían sal sumaban entre 20 y 21 en 1566 (AGI, Justicia 461, f. 1468). Siete u ocho pescadores aparentemente conformaban un grupo que le presentó una petición al Dr. Cuenca en 1566 (AGI, Justicia 457, f. 1440v). Los documentos referidos a la encomienda de Túcume en 1541 muestran 20 "indios tamberos" y alrededor de 100 pescadores (el grupo de especialistas más grande mencionado en el manuscrito) (ART, CoO, 13-VII-1570). Otra referencia a la costa central sugiere que el total de artesanos sumaba entre el 6 y $7 \%$ de la población de una comunidad (Ramírez: "La organización económica de la costa norte: Un análisis preliminar del período prehispánico tardío", en Castelli, Amalia, et. al, (comps.): Etnohistoria y antropología andina, Museo Nacional de Historia, Lima, 1981, pág. 293, n. ${ }^{\circ} 14$.

52 Hay evidencias de almacenaje de ropa. Un "ropero" (¿alguien que hacía y/o almacenaba ropa?) estaba a cargo de cientos de piezas de ropa en 1566 (AGI, Justicia 458, f. 2248v).

53 Aún se debate si éstos eran artesanos a tiempo completo. Netherly cree que sí ("Organization through Opposition: Dual Division and Quadripartition on the North Coast of Peru", ponencia presentada en la Annual Meeting of the American Anthropological Association, Houston, Texas, 1977a; "Local Level Lords on the North Coast of Perú", tesis de Ph.D., Universidad de Cornell, Ithaca, Nueva York, 1977b, pág. 202). Rostworowski ("Mercaderes...", pág. 126) informa de que ciertos artesanos tenían acceso a la tierra y que, por lo tanto, lo eran a medio tiempo, una conclusión compartida por Ravines, Rogger (comp.): Tecnología Andina, Instituto de Estudios Peruanos, Lima, 1978, pág. 93. Su estatus en este sentido podría haber dependido de la ocupación desempeñada. AGI, Justicia 457, f. 848v; Justicia 458, f. 1800v; Justicia 461, f. 1456-56v, 1514v-15; Justicia 418, 1573, f. 217; Morúa, Historia ..., pág. 329.

54 British Museum, Add. 13992, f. 412; AGI, Justicia 457; Justicia 461, f. 995v y 1400-v para Íllimo; y Patronato 97, R. 4 (1569) para Chérrepe.

55 Rostworowski: "Mercaderes...", pág. 126; Lechtman: "Issues”, pág. 25; Shimada, Izumi; Epstein, Stephen, y Craig, Alan K.: "The Metallurgical Process...", pág. 38; Jara: "La producción de metales preciosos en el Perú en el siglo XVI", Anales del III Congreso nacional de Historia del Perú, 
Los nativos también fabricaban naipes en la época prehispánica, así como planchas, cuentas y pedazos más grandes de metal, descritos en diversos textos hispanos como barretillas (pequeñas barras), tejuelos (pequeños lingotes o pedazos), planchas, "ojas" y platos, cuya forma y distribución han provocado un amplio debate con respecto a su uso. Algunos estudiosos creen que los objetos eran comercializados o usados como medios de cambio estandarizados. ${ }^{56}$ Otros piensan que tal vez fueron usados como armadura y que se les cosía a la ropa. Heinrich UbbelohdeDoering informó de un descubrimiento arqueológico que consistía en un casco con discos de cobre dorado que se superponía como escamas. Recordemos que los actuales pueblos andinos siguen usando monedas para decorar la ropa. ${ }^{57}$

Asimismo, los cronistas afirman que los pedazos de metal se empleaban en los entierros. Los arqueólogos lo han verificado al encontrar que en los entierros mochicas, sicán y chimú, los muertos a menudo tenían objetos de cobre en sus manos, brazos, pies, labios y en la boca. ${ }^{58}$

\section{Tributo}

Los curacas entregaban los objetos de metal producidos con el trabajo de sus súbditos al estado, lo que a menudo implicaba su transporte a tierras lejanas. Una fuente anónima dice así:

"Que antiguamente Ponian los tributos en los tambos de los caminos rreales y que los mas dellos hera fuera de sus naturalezas y En el cuzco y demas partes que se les mandaba y en fronteras y fortalezas harto bien lexos de sus tierras." ${ }^{59}$

Centro de Estudios Histórico-Militares del Perú, Lima, 1963, págs. 134-42, pág. 137; ART, CoR, 30-VI1576; CoO, 11-VII-1582; AGI, Justicia 457, f. 1073v; Justicia 461, f. 868v; Shimada: "Economy of a Prehistoric Urban Context: Commodity and Labor Flow at Moche V Pampa Grande, Peru", American Antiquity, 43, 4, 1978, pág. 582; Rostworowski: "Mercaderes...", págs. 125, 135 y 136; Duviols: Cultura Andina y represión, Centro de Estudios Regionales Andinos "Bartolomé de las Casas", Cuzco, 1986.

56 Nos vemos tentados a afirmar que esta interpretación comercial [trading] ahora tiene una sólida base histórica. Pero la cita no nos dice si los pueblos de la costa recibían menas o naipes a cambio de alimentos y ropa. Ver también Ramírez: "Un mercader...".

57 Franch: "La producción...”, pág. 319; Shimada: "The Sicán Culture: Archaeological Characterization”, inédito, 1984, págs. 44-48; Ubbelohde-Doering, Heinrich: On the Royal Highways of the Inca, Thames and Hudson, Londres, 1967; Espinoza Soriano: "El Valle de Jayanca...", págs. 268, 270-271.

58 Alva, Walter, y Donnan, Christopher: Royal Tombs of Sipan, University of California Press, Los Ángeles, 1994; Ubbelohde-Doering: Royal Highways, págs. 81-93; Shimada, comunicación personal, marzo de 1985. Véase también Lechtman: "Issues...”, págs. 22-23; Ramírez: The World Upside Down... 59 BAH, A92, f. 20. 
En 1540, Cristóbal de Barrientos preguntó a los señores de Cajamarca qué otros nativos (identificados como mitimaes) vivían entre ellos que no fueran súbditos suyos. Parte de la respuesta dice así:

\footnotetext{
"los caçiques de caxasmayo [Pacasmayo] y saña e col[1]ique [Collique] e chuspo e çinto e tuvone [Túcume] todos los quales d[ic]hos caçiques dixeron los di[ch]os Ss[eño]r[es] de caxamarca que tenian puestos sus mytimaes en la d[ic]ha tierra de caxamarca para que cada caçique de los susod[ic]hos pudiesen servir mas sin travajo al puga [ynga] y poner los tributos porque contribuian al ynga en los tambos de caxamarca..." ${ }^{60}$
}

Esto indica que los pueblos costeños también tenían que entregar bienes de tributo a los centros situados en la sierra. Otra fuente temprana afirma que el tributo era llevado a Cuzco desde lugares tan alejados como Quito. Santillán afirma en general que "[el] oro y plata que sacaban de las minas y chipanas y brazaletes, todo esto lo llevaban al Cuzco sin que quedase cosa en poder del curaca". ${ }^{61}$

Probablemente no causaba problemas pues las cantidades producidas eran pocas, "porque alli [Cuzco] se traya [tributo] para el inga y su gente de toda la t[ie]rra pero avia una orden que de las t[ie]rras que estavan lexos se traya poco", comenta la fuente anónima de 1561. Santillán menciona que "en la provincia que habia plateros, le daban chipana [manillas, pulseras, brazaletes], en poca cantidad, porque una guaranga dicen que daba una chipana...". Y a cambio, según la "Horden" citada, "[e]l ynga Pagaba los tales caciques ansi como el rrey paga a Sus corregidores y la paga hera alguna rropa de su bestir o algun baso de oro y plata quando le yban a ver por via de $\mathrm{m}[\mathrm{e}] \mathrm{r}[\mathrm{ce}] \mathrm{d}$ q[ue] les hazia". ${ }^{62}$

De este modo, en líneas generales parece probable que los pueblos de la costa hayan extraído cobre y otros minerales bajo la supervisión de sus curacas en los depósitos que descubrieron y administraron. Además, los curacas tal vez enviaban a sus súbditos a conseguir minerales adicionales en depósitos más distantes. Allí o bien intercambiaban un tipo de bien (hilo de algodón o ají) por minerales, o incluso productos terminados (aparentemente el mecanismo imperante antes de la conquista incaica) o, lo que es más probable, trabajo — el cual podría haber tomado la forma de parte de

60 AGI, Justicia 1063, n. ${ }^{\circ} 3,1570$, f. 9.

61 AGI, Patronato 188, R. 22, f. 20; Santillán: Relación..., pág. 51.

62 AGI, Patronato 188, R. 22, f. 20v; Santillán: Relación..., pág. 39; British Museum, Add. 13992, f. 412. Véase también BAH, A92, f. 28. 


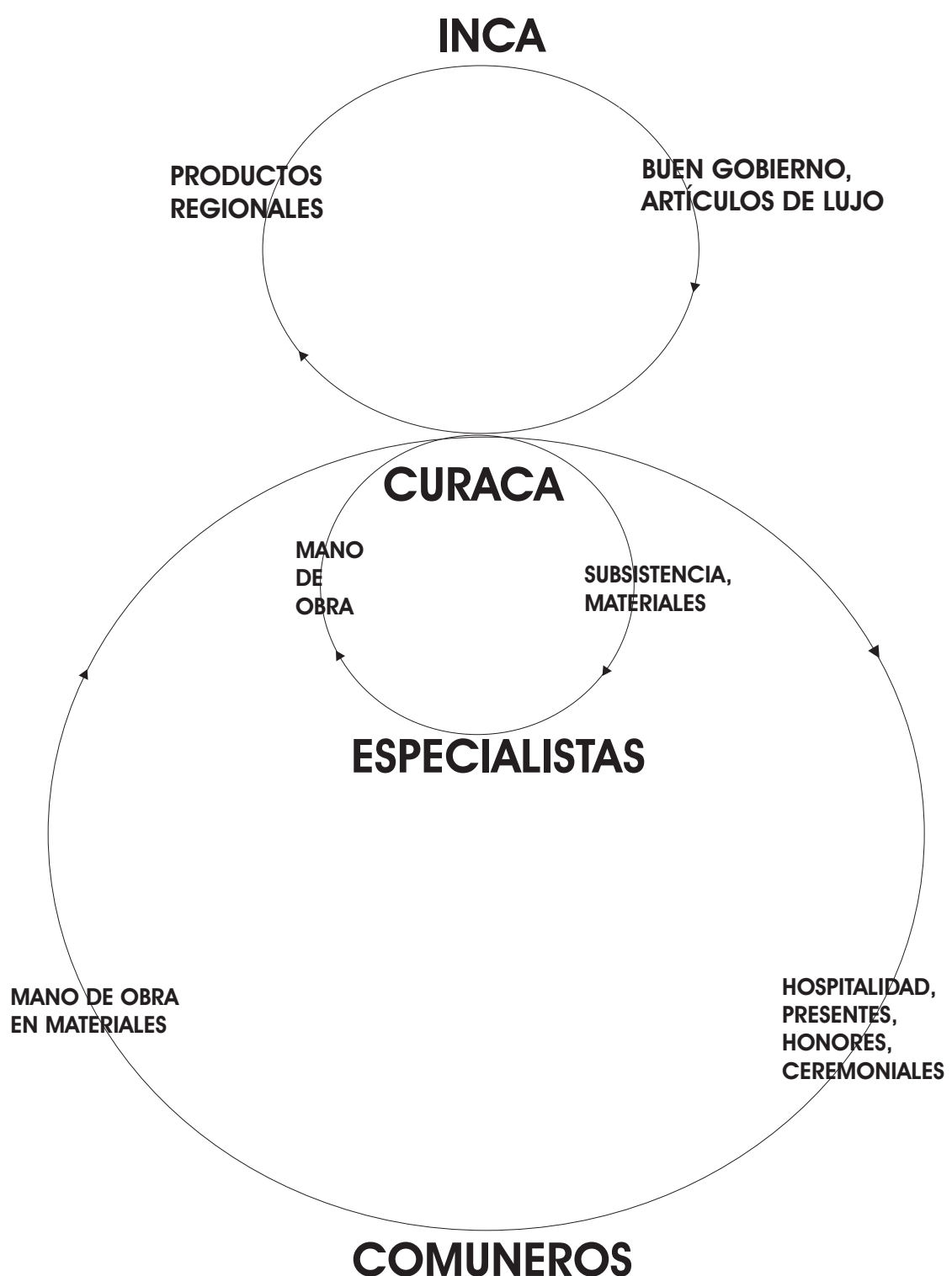

AEA, 64, 1, enero-junio, 2007, 175-208. ISSN: 0210-5810 
las menas extraídas por los trabajadores visitantes- a cambio del acceso a los recursos (al parecer el mecanismo vigente tras la conquista inca). En este último caso, los señores de la sierra probablemente daban a los trabajadores costeños acceso a los depósitos de minerales, pues el anfitrión podría beneficiarse recibiendo tal vez presentes exóticos de la costa y parte de lo producido por el trabajo de los visitantes. Esta generosidad asimismo mejoraba el prestigio y la reputación de su persona y su clientela. Ya fueran extraídas de depósitos de la costa o no, las menas eran llevadas de vuelta al centro administrativo del señor para su transformación. Los curacas entregaban algunos de los bienes resultantes al inca y a su vez recibían a cambio otros para sus propias necesidades personales y rituales. Todo el proceso parece haber sido redistributivo y haberse efectuado bajo el control estatal, lo que respalda al registro arqueológico tal como lo interpreta Shimada. El caso de los incas puede resumirse esquemáticamente con la figura de la página anterior. ${ }^{63}$

\section{La metalurgia en la costa norte en la época virreinal}

La invasión y el posterior asentamiento español perturbó seriamente este patrón de obtención y producción. En Cajamarca, en 1532 y 1533, los nativos entregaron al pequeño ejército invasor de Pizarro 2.475 .302 pesos de oro, o un total de 600.655.410 maravedíes de metales preciosos, que habían acumulado durante décadas y tal vez siglos. Sin embargo, los españoles insistieron en encontrar más. ${ }^{64}$

Las primeras mercedes de encomienda reflejan dicho interés, ya que los encomendados podían ser empleados para trabajar en las minas, incluso en aquellos distritos donde se sabía que éstas no existían. La libertad plena que las primeras mercedes implicaban dio a personas como Melchor Verdugo, el encomendero de los Cajamarca, la autoridad necesaria para enviar a cientos de personas a los pozos. Ya en 1540 Verdugo, que luego sostuvo ser el primer español en descubrir y explotar las minas de plata de Perú, presionó a los señores de los Cajamarca con amenazas de muerte y otros medios, para que cada uno enviara 100 hombres a las minas de Chilete. La visita de Barrientos dice así:

63 Shimada: "The Sicán Culture..."

64 Bargalló: La minería..., págs. 68, 101; Jara: "La producción de metales preciosos...", págs. 138 y 142 
"Ay en la d[ic]ha tierra de caxamalca minas de plata en las quales el visitador vio sacar plata e andar en ella sirviendo los d[ic]hos y[ndi]os de caxamalca. Los señores de caxamalca dijeron que cada uno dellos dava de servicio ordinarios en las $\mathrm{d}[\mathrm{ic}] \mathrm{has}$ minas de plata 100 personas de servicio." ${ }^{65}$

Esto implica que de 600 a 700 hombres fueron despachados a trabajar en esas minas, posiblemente muchos más de los que jamás fueron enviados por los incas, que (como ya se ha mencionado) usualmente requerían que uno de cada cien cumpliera esta obligación. ${ }^{6}$

La Memoria de 1548, publicada por Rafael Loredo, estima que los 3.000 nativos de encomienda que Verdugo seguía controlando para la fecha producían 6.000 pesos de renta al año en las minas. ${ }^{67} \mathrm{Al}$ parecer, los mil indios que Verdugo perdió con Hernando de Alvarado (de los 4.000 que originalmente tuvo), debido al arreglo y redistribución de encomiendas efectuadas por la corona, podían producir casi tanto en las minas como los 3.000 que aún le quedaban. La Memoria calcula que los súbditos de Alvarado podían producir de 5.000 a 6.000 pesos al año, y enumera las restantes encomiendas en que los nativos tenían acceso a las minas y cuánto valía dicha producción. De esta manera, en la sierra, en comparación con la costa, la mayoría de los tributarios de las encomiendas podría haber tenido - y tal vez tenía - acceso a las minas ${ }^{68}$

Las cifras de la Memoria parecen ser algo elevadas. En ese mismo año, la tasa de Gasca para Cajamarca especificaba que los nativos debían entregarle al encomendero 2.100 pesos anuales por valor de 450 maravedíes cada uno, ya fuera en oro o plata según aquél lo deseara. Gasca entonces añadió lo siguiente:

"e si vos los di[ch]os caçiques e yndios quisieredes sacar los di[ch]os dos myll e cien p[es]os de las minas en tal casso el encomendero sea obligado de os dar e sustentar los fuelles y herramientas que fueren menester $\mathrm{C}$ para sacar e fundir la di[ch]a plata vos los di[ch]os caçiques e yn[di]os dareys al di[ch]o v[uest]ro encomendero trezientos $\mathrm{p}[\mathrm{eso}] \mathrm{s}$ mas $\mathrm{p}[\mathrm{ar}] \mathrm{a}$ conprar y sustentar los di[ch]os fuelles e herramientas que sean

65 AGI, AL 201, 1633 para Túcume en 1536; Justicia 415, f. 199; Justicia 1063, n. 3, 1570; Busto, José Antonio del: "El capitán Melchor Verdugo...”, págs. 330, 364.

66 Santillán: Relación..., pág. 39. Véase también AGI, Patronato 185, R. 21 para la evaluación que el licenciado Vaca de Castro hiciera de la mina de plata que Verdugo tenía en Cajamarca, en oposición a las del resto del virreinato.

67 La Memoria de Loredo (Los repartos...) reporta que Verdugo perdió la tercera parte de su encomienda. La cifra de una cuarta parte, dada por del Busto, es más cercana a las cifras reales dadas en la visita en AGI, Justicia 1063, n. ${ }^{\text {o } 3,1570 . ~}$

68 Loredo: Los repartos..., págs. 255-256, 259-264. 
por todos dos myll e quatro cientos p[es]os cada un año pagados de quatro en quatro meses." ${ }^{6}$

Sin duda, Gasca está recordando un decreto de 1549 que prohibía a los encomenderos enviar indios de encomienda a las minas so pena de perder su merced y una multa de 100.000 maravedíes, porque agregó que Verdugo no podía obligar a los cajamarquinos a trabajar en las minas. La elección de cómo obtener el tributo en metal era de ellos. ${ }^{70}$

Verdugo no quedó satisfecho, a pesar de la cantidad y productividad de los cajamarquinos. Repetidas veces se lamentó de que sus encomendados no producían nada de oro, lo cual evidentemente era una exageración puesto que él enviaba oro a su madre en España con regularidad. Todavía en 1556, Verdugo seguía importunando a los serranos para conseguir el metal precioso. Los curacas de algún modo encontraron oro que darle en el transcurso de sus inspecciones personales de sus asentamientos. ${ }^{71}$

Lo hicieron por temor. Verdugo tenía una reputación de ser un déspota cruel. Las autoridades eventualmente lo enjuiciaron porque su crueldad en las minas ocasionó la muerte de mineros nativos. En otra ocasión, en el pueblo de Bambamarca, permitió que un perro de caza descuartizara al hijo de un curaca que había intentado excusarse de darle el metal precioso. $^{72}$

Los encomenderos también obligaron a los curacas y principales a conseguir los metales preciosos en zonas donde no se sabía de la existencia de minas. En Jayanca, por ejemplo, los señores costeños tuvieron que buscar oro y plata. Según el testimonio de 1540, el principal Labamy y sus casi 200 súbditos vivían entre los túcume, en la sierra de los Guambos, y daban a su curaca nueve platos de plata cada tres meses lunares. ${ }^{73}$ El curaca de Jayanca le entregaba a Francisco Lobo, su encomendero, diez tejuelos de oro y barretillas de plata cada dos meses lunares; además, dos principales le daban tres tejuelos y barretillas de plata, y una de oro. Asimismo, el principal Facollapa, encomendado a Diego Gutiérrez, le entregaba cinco pequeñas barras de plata cada tres meses lunares, o cuatro o cinco tejuelos

69 AGI, Justicia 415, f. 127v-128.

70 Bargalló: La minería..., pág. 83.

71 Busto, José Antonio del: "El capitán Melchor Verdugo...”, págs. 326-327.

72 Busto, José Antonio del: "El capitán Melchor Verdugo...”, págs. 363-365; AGI, Justicia 415, f. 1-1v, 72v.

73 Espinoza Soriano ("El Valle de Jayanca...", pág. 257) afirma que Labamy dio tres platos de plata a su señor, cuando en realidad el testimonio de la visita que él transcribe y publica dice nueve (pág. 268). 
de oro, dos de sus principales también daban a Gutiérrez dos tejuelos de plata. $^{74}$

Sin embargo, el curaca de Jayanca sostuvo que no había minas de plata u oro bajo su jurisdicción; lo que entregaban a su "amo" "lo rescata[ba]n el y sus prencipales". Ello implica que el estado (el gobierno) controlaba el proceso de obtención. El término "rescate" 75 podría implicar el trueque o el intercambio de bienes (como usualmente se le define) o un intercambio de trabajo. $^{76}$

Otras comunidades de la costa, como Saña, también se vieron obligadas a encontrar plata para su encomendero. La tasa de Gasca para Saña, fechada en 1549, afirma que los 1300-1500 tributarios debían pagar "dozientos pesos de ley perfect en oro o plata", pese a no conocerse ninguna mina bajo su control. ${ }^{77}$

No sabemos si esta obligación estaba diseñada para obligar a los de Saña a ingresar en la economía monetaria, y/o si se esperaba que obtuvieran los pesos a través de su trabajo o del intercambio de bienes. A favor de la primera explicación está el hecho de que ya en 1556 los españoles tenían que hacer frente a una escasez de mano de obra. Los nativos ya no deseaban trabajar para los españoles: debía obligárseles. Un español se quejó del siguiente modo:

"los yndios se alquilan $\mathrm{p}[\operatorname{ar}] \mathrm{a}$ guardar ganados y $\mathrm{p}[\mathrm{ar}] \mathrm{a}$ labores q[ue] hay en este valle podrian ganar su tributo...; ellos de mala gana van a cosas semejantes aunque los españoles les rruegan con la plata y q[ue] siempre dizen q[ue] estan ocupados en sus haziendas sino es con mandami[ent]o o provi[ci]on no quieren trabajar por q[ue] no son amigos de adquirir haziendas mas de para el presente." ${ }^{78}$

74 Espinoza Soriano: "El Valle de Jayanca...”, págs. 270-271. ¿Acaso el hecho de que únicamente ciertos principales entregaban tributo en plata indica que eran productores especializados de esta sustancia?, ¿o más bien señala que tenían una capacidad (¿o ubicación?) especial para conseguirla, con la que los restantes señores y sus súbditos no contaban?

75 Se define "rescatar" como "recobrar por precio o por fuerza lo que el enemigo ha cogido, y por extensión, cualquier cosa que pasa a mano ajena; cambiar o trocar oro u otros objetos preciosos por mercaderías ordinarias; redimir la vejación; librar del trabajo o contratiempo; recobrar el tiempo o la ocasión perdidos" (Real Academia Española: Diccionario de la lengua Española, Espasa-Calpe, Madrid, 1970, pág. 1137).

76 Espinoza Soriano: "El Valle de Jayanca...”, págs. 257, 270. En la época precolombina podría haber querido decir intercambio de trabajo y eventualmente haber significado un trueque en el sentido de intercambio de bienes, a medida que el sistema de reciprocidad y redistribución se desintegraba. Si nuestra suposición es correcta, los españoles usaron rescate de un modo y los indios, inicialmente al menos, de otro. No hay evidencia de que hubiera minas explotadas por los Jayancas.

77 BAH, 9-4664, f. 23v.

78 ANP, Derecho Indígena (DI), 1. 2, c. 26, 1580, f. 403v. 
Así, el Dr. Cuenca dictó ordenanzas que especificaban el jornal que debía pagarse a los jornaleros de la villa de Saña y todas las comunidades vecinas; además otorgó a los indios mayores oportunidades para que conmutaran sus obligaciones tributarias en dinero, así como su número decreciente. Todo sugiere que la razón subyacente a sus actos era forzarles a ingresar en la economía monetaria. Los nativos serranos de Guambos se quejaron de que su tributo en plata era demasiado alto, pues "los indios de guambos son pobres, no tienen minas y estan como estan tan adentro del trato de los españoles q[ue] no tienen a que ganales [los pesos o la plata]". Las exacciones tal vez irreales, así como la crueldad de algunos de los encomenderos, auxiliados por oficiales reales como el Dr. Cuenca, son otras dos razones adicionales de por qué la tasa de mortandad indígena se disparó y por qué muchos de ellos huyeron. ${ }^{79}$

La visita del Dr. Cuenca a la región trajo consigo mayores y más sistemáticos cambios en la economía política de los señoríos, que habrían de tener serias implicaciones para la minería en el norte. Entre sus medidas estaban la continua reubicación de los indios en lugares céntricos: reasentó los centenares de hogares, aldeas y caseríos dispersos de Jayanca en tres pueblos. Por lo tanto, ya no era posible despachar o mantener súbditos explotando recursos lejos de sus nuevos hogares. ${ }^{80}$

Otras medidas tuvieron efectos de gran alcance sobre la economía indígena como, por ejemplo, la restricción de los viajes, lo que limitó la movilidad física de los nativos; o la revisión del tributo de cada curaca y sus súbditos. Por último, Cuenca prohibió a los señores que invitaran a sus trabajadores a que bebieran chicha, como era su costumbre cuando trabajaban juntos. Para mediados de la década de 1560, el efecto de estos cambios fue el quiebre de todo el sistema económico encabezado y regulado por el curaca y los principales. Los súbditos ya no trabajaban para ellos a menos que los caciques tuvieran los medios para cumplir las obligaciones esperadas de reciprocidad y redistribución, que eran la piedra angular de la obediencia y la producción en masa.

Así, durante los primeros 35 años posteriores a la conquista, el curaca ya no podía enviar fácilmente a grupos de "intercambiadores" o de trabajadores a conseguir los minerales: el viaje estaba prohibido. La necesidad disminuía a medida que los nativos eran obligados a trabajar para los

79 AGI, Justicia 457, f. 740; Justicia 458, f. 1550v-51; Justicia 461, f. 1260-61.

80 Ramírez: "Chérrepe...”; "Social Frontiers...”, pág. 425; AGI, Patronato 189, R. 11, 1566. 
españoles al jornal diario prescrito, además estos últimos ofrecían comprarles con dinero los productos de sus campos y ganado. ${ }^{81}$

De igual modo, la escasez cada vez más aguda de trabajadores probablemente impidió a los curacas enviar indios a que extrajeran minerales, incluso aquellos encontrados en la costa, como lo hacían antes de la invasión española. Sin embargo, en un principio la minería del cobre aparentemente prosiguió como antes, pues en 1566 unos cuantos nativos de la zona empleaban cobre y plomo como moneda; otros usaban tejos o "pancitos" (pequeños cubos o pedazos) de plata. La moneda de este metal no circuló con regularidad hasta décadas después. Los implementos fabricados por ellos mismos también fueron reemplazados con rapidez por otros de cobre, importados tempranamente del Viejo Mundo y posteriormente de Chile. ${ }^{82}$

La desintegración de la economía política indígena queda ejemplificada con el destino de los plateros. La "Horden" citada antes dice en este sentido que los "plateros q[ue] En tiempo de Ynga hacian de joro y plata las basijas y otras obras... ya no viben Entre los yndios por que no hallan a que ganar de comer sino En las ciudades donde lo ganan entre españoles. ${ }^{83}$

Con todo, los trabajadores nativos dominaron el proceso de fundición y el trabajo de los metales preciosos hasta la década de 1570. Debido a la tecnología, la producción siguió dependiendo de las menas de alta calidad y era de escala relativamente pequeña e intensiva en mano de obra, un patrón que aparentemente se remonta al período Sicán Medio. ${ }^{84}$

En 1560 el portugués Enrique Garcés logró obtener 400 marcos de plata usando el beneficio por azogue y 12 años después el español Pedro Fernández de Velasco, respaldado por el virrey Toledo, experimentó con éxito con el proceso de amalgama (perfeccionado originalmente en Nueva España) usando mercurio y sal. En el sur, donde el proceso fue aplicado por primera vez, las menas fueron mezcladas con mercurio, sal y, a veces, con otros ingredientes en tanques de piedra o recipientes recubiertos con azulejos. El calor aceleraba el proceso de amalgama. Este desarrollo tec-

81 Ramírez: Provincial Patriarcas..., capítulo 4, apéndice 3.

82 AGI, Justicia 456, f. 719, 837v, 879.

83 British Museum, ADD. 13992, f. 415.

84 Bargalló: La minería..., pág. 91; Morúa: Historia..., pág. 279; Cobo: Historia..., I, pág. 151. 
nológico permitió usar las menas de menor calidad y asimismo incrementó la escala de la producción. ${ }^{85}$

En el norte, el proceso de amalgama se llevaba a cabo en tinas o cajones de 50 quintales de mineral cada uno y, para finales del siglo XVI, el proceso ya se efectuaba sin calor. Este avance tecnológico significó que los españoles tomaron el control del proceso de refinamiento, aunque siempre dependieron de los indios para la mayor parte del trabajo manual. Es evidente que la fundición ya se hallaba establecida en la costa norte, lo demuestra un documento encontrado en el Archivo de Cayaltí (un complejo agro-industrial azucarero ), referido al siglo XVI: Gaspar de Coria (n. 1545-1551), un temprano residente y estanciero de los valles de la costa norte, tenía en funcionamiento un "ingenio de moler metales con cuatro hornillos" cerca de Sipán, donde - como menciona Lechtman - fueron hallados varios grandes panes o lingotes de cobre vaciado. ${ }^{86} \mathrm{~A}$ comienzos de la década de 1970, junto con un geólogo, visité Sipán (en el valle de Lambayeque, a trece kilómetros de Saña), cerca de las posesiones conocidas de Coria: aún se podían ver las bases de los hornos.

Hay que señalar, sin embargo, que a lo largo de la época virreinal, la mayor parte del cobre empleado en la costa para hacer calderas y trapiches para la industria azucarera era importado. El Padre Acosta dijo: "se sirven de lo [de cobre] que va de España o de lo que a vueltas del beneficio de oro y plata resulta." Pero salvo por la referencia al ingenio de Coria, no se encontró ninguna otra referencia al refinamiento del mineral en la costa durante el virreinato. ${ }^{87}$

En los siglos XVI y XVII la minería parece haber sido de dos tipos. En la costa norte, el único padrón oficial de las actividades "mineras" 88 figura en copias de los registros de personas que habían descubierto tesoros enterrados. El ejemplo más espectacular y completo es el expediente de

85 Brading, David A., y Cross, Harry E.: "Colonial Silver Mining: Mexico and Peru," Hispanic American Historical Review, VII-4, 1972, págs. 552-555. Para una descripción de los procesos de extracción y refinamiento en Potosí, véase Bargalló: La minería ..., págs. 83, 91-103; Lohmann Villena: "La minería...", págs. 644-645; Contreras: “Técnicas...", págs. 49-50.

86 Archivo de Cayaltí, 1920; ART, IC, 16-III-1785; CoO, 27-VII-1580 y 30-IX-1582; ANP, Residencia, 1. 22, c. 57, 1611, f. 185v; RA, 1. 23, c. 123, 1614, f. 129; Mogrovejo: "Diario...", pág. 237; Lechtman: "A Metallurgical Site Survey..., pág. 14.

87 Ramírez: Provincial Patriarcas..., capítulo 6; Acosta, Joseph de: Historia natural y moral de las Indias, Fondo de Cultura Económica, México, 1590/1979, pág. 144. Cobo (Historia..., I: 151), en cambio, informa acerca de que algo de cobre se extraía en Charcas y Chile. la costa.

88 Excepción hecha de un voluminoso registro [record] de la minería de la cal y el azufre en 
la licencia y saqueo de la huaca Yamayoguán, uno de los palacios-mausoleos de Chan Chan, iniciado en 1558 y del cual se extrajeron 144.612 pesos de plata y 21.859 de oro en dos años. Otras "huacas" también fueron fuente de grandes hallazgos a mediados del siglo XVI. De hecho, los funcionarios ediles subsidiaban estas actividades "mineras" ya en 1562, asignando mitayos para que ayudaran a excavar y desmantelar las estructuras. De los 882 trabajadores nativos asignados a todas las actividades de la mita, el $46 \%$ fue específicamente destinado a que excavara en huacas. La distribución de la mano de obra indica que la extracción de tesoros enterrados era un gran negocio, importante para los vecinos y el rey. ${ }^{89}$

Otra denuncia y registro de un "entiero escodixo o mina de tesoro de oro o plata o otro xenero de metal" cerca del asentamiento nativo de Santiago fue hecha en dos ocasiones distintas: primero por Simón de Silva y el maestre de campo don Luys Joseph de Mora, cacique principal (curaca) y gobernador del valle de Chicama, en 1684, y después por Simón de Silva y don Juan Galindo, un sacerdote, en 1686. Luego, don Melchior Chamo Chunbi, un nativo del pueblo de Nuestra Señora de Jequetepeque, denunció una "guaca entierro o escondedijo de plata oro piedras pressiosas" que estaba a tres calles de la ciudad de Trujillo, cerca del molino llamado "del Viento". De este modo, las actividades "mineras" de la costa estuvieron limitadas, según lo muestra el registro oficial, a la recuperación de tesoros indígenas antiguamente enterrados, lo que en esencia viene a ser pillaje. ${ }^{90}$

En el hinterland serrano de la costa, sin embargo, los españoles y criollos estaban descubriendo y trabajando depósitos naturales. ${ }^{91}$ La mayoría de las referencias a la minería de la plata provienen de los distritos de Cajamarca y Guamachuco. Las primeras datan de 1638. Posteriormente, un aspirante a minero declaró haber explorado los cerros de Cajamarca

89 Ramírez: The World Upside Down..., págs. 128-130. Por los impuestos que los grandes hallazgos generaban: ART, 1562.

90 ART, Judicial (Jud.), Real Hacienda (R.H.), Pedimento (Ped.), 1. 153, c. 670, 7-VII-1684; c. $673,23-X-1686$; c. $676,19-$ II-1691. Cada calle era de 144 por 12 varas [0.84 metros], según las define Mörner, Magnus: Perfil de la sociedad rural del Cuzco a fines de la colonia, Universidad del Pacífico, Lima, 1978, págs. 167-168; véase también Alonso Pedraz, Martín: Enciclopedia del idioma, Aguilar, Madrid, 1958, pág. 1280. Don Juan de Collique conocía otra huaca en donde había plata escondida. Se la ofreció al Dr. Cuenca en 1566 para evitar que le ahorcaran. No sabemos si le mencionó la ubicación a alguien antes de morir (AGI, Justicia 457: 1178v).

91 Hay una denuncia de un "entierro escondedijo o guaca de oro y plata" en la sierra, en la montaña llamada "San Martín", entre los pueblos de Contumasa y Cascas (ART, Jud, R.H., Ped., 1. 153, c. 674, 9-IX-1689). Sin duda hubo muchos más descubrimientos que jamás fueron registrados. 
durante seis años antes de hacer su descubrimiento. Al mismo tiempo había personas lavando oro en los asientos de San Juan de Parcoy [Porcoy?] y San Pedro de Pataz, más hacia el interior. Para finales del siglo XVII, las cuentas de la caja real muestran que la minería era llevada a cabo por varias personas distintas, la mayoría de las cuales sólo había sido denunciada una vez. ${ }^{92}$

\section{La organización de la minería en el norte}

El presente estudio es un primer intento de describir la importancia que la minería y la metalurgia tuvieron dentro del contexto de la organización socioeconómica de la costa norte en los siglos XVI y XVII. El cuadro que se desprende de las fuentes y descubrimientos disponibles para el período prehispánico es el de un sistema indígena de abastecimiento y producción que satisfacía las necesidades de la comunidad y el estado. Bajo el dominio de los incas, un señor asignaba una parte relativamente pequeña de sus súbditos, por un breve lapso o de forma rotativa, para que consiguieran menas tanto en la costa y quizá también en el hinterland serrano. Los minerales eran transportados a los talleres centrales, probablemente cerca de la residencia del curaca, donde los trabajadores las fundían y pasaban a ser las materias primas para los orfebres más especializados, que fabricaban los bienes terminados a cambio de su mantenimiento y prestigio. Al parecer, los objetos de oro y plata ingresaron en el sistema redistributivo del estado imperial inca. Los objetos utilitarios, rara vez mencionados en las fuentes manuscritas hispanas, probablemente entraban en las redes redistributivas locales, y eran asignados por el señor a quienes los necesitaban o merecían, por ejemplo, anzuelos de cobre o bronce a los pescadores; implementos agrícolas, como las rejas de las azadas, para los agricultores y herramientas domésticas, como agujas y cuchillos tumi, a tejedores y cocineros, respectivamente.

Este cuadro general se disgregó con rapidez debido a la invasión española. Los primeros españoles llegados al norte habían arriesgado su vida por la oportunidad de conseguir riquezas: primero tesoros, y luego súbditos nativos que cumplieran su voluntad, tal como sucedía en la sociedad

92 ART, Jud., R.H., Ord., 1. 125, c. 15, 18-IV-1638; Jud., R.H., Ped., 1. 153, c. 680, 9-VII1693; Jud., R.H., Asuntos de Gobierno (AG), 1. 146, c. 405, 28-III-1696; ART, Administracion Hacienda., 25, Libro de Cuentas, Truxillo, Manual, 1692-1693. 
que habían dejado en la Península Ibérica. El éxito fue definido por el metálico y la posición y el status que éste podía comprar. Dados sus objetivos, la presencia misma de los conquistadores produjo el desmantelamiento de la economía política nativa. Las enfermedades diezmaron las etnias indígenas; la población superviviente fue concentrada en reducciones para facilitar el cobro del tributo, la conversión religiosa y el control. Este reasentamiento significaba no sólo la pérdida de sus hogares, sino también de sus chacras tradicionales y otros recursos que los españoles posteriormente desecharon porque aseguraban que quedaban demasiado lejos como para ser utilizados de modo eficaz. Las demandas tributarias de trabajo y artículos exóticos - como lo era el oro para muchas personas de la costa - consumieron un monto desproporcionadamente grande de la mano de obra y restaron tiempo a otras tareas. Por último, las proscripciones dictadas por la corona con respecto al tributo, los viajes y la hospitalidad - tal como las interpretara e implementara el Dr. Cuenca en la década de 1560 - y la interferencia de los encomenderos españoles con la sucesión y las bases de la legitimidad minaron la posición y el poder de los señores, hasta el punto de que su palabra y órdenes fueron cuestionadas, e incluso ignoradas o desobedecidas. Al mismo tiempo, la mano de obra indígena fue gradualmente expropiada del control de los señores por medio de la creciente economía de mercado. Parte de esta mano de obra fue encauzada hacia las minas, sobre todo las de plata, ubicadas en las cercanías de las ciudades y villas españolas del norte. La escala de las operaciones se multiplicó con la introducción del proceso de amalgama en la década de 1570. Para ese entonces, la mayor parte de las huellas del sistema indígena se había desvanecido y reemplazado por un sistema de gran escala controlado por los españoles y diseñado para cumplir con sus objetivos. Irónicamente, la población nativa siguió suministrando el grueso de la mano de obra para las actividades extractivas. Asimismo, los orfebres fueron forzados a dejar la corte de sus señores indígenas tradicionales y pasaron a depender de sus nuevos señores: los españoles.

Recibido el 7 de septiembre de 2005 Aceptado el 15 de enero de 2006 



\section{Cuadros}

\section{CuAdro I}

LA MINERÍA EN EL NORTE DE PERÚ, 1790

\begin{tabular}{|c|c|c|c|c|c|c|}
\hline Distrito & $\begin{array}{c}\text { Número } \\
\text { de } \\
\text { Mineros }\end{array}$ & $\begin{array}{l}\text { Minas de } \\
\quad \text { Plata } \\
\text { Trabajadas }\end{array}$ & $\begin{array}{c}\text { Minas de } \\
\text { Plata } \\
\text { Abandonadas }\end{array}$ & $\begin{array}{l}\text { Minas de } \\
\text { Oro } \\
\text { Trabajadas }\end{array}$ & $\begin{array}{c}\text { Minas de } \\
\text { Oro } \\
\text { Abandonadas }\end{array}$ & $\begin{array}{l}\text { Ingenios } \\
\text { de Plata }\end{array}$ \\
\hline Hualgayoc & 106 & 107 & 152 & 0 & 0 & 60 \\
\hline Pataz & 36 & 17 & 4 & 2 & 1 & 17 \\
\hline Huamachuco & 22 & 11 & 2 & 0 & 0 & 5 \\
\hline Cajatambo & 13 & 26 & 0 & 0 & 0 & 13 \\
\hline Conchucos & 7 & 14 & 0 & 0 & 0 & 0 \\
\hline $\begin{array}{l}\text { Asiento Real } \\
\text { de Conchucos }\end{array}$ & 5 & 10 & 0 & 0 & 0 & 5 \\
\hline
\end{tabular}

Fuente: AGI/AL1352, 30-VI-1790. También: AGI/AL1353, 1790 y BNP/C700, 1790 donde hay datos ligeramente diferentes.

\section{CUADRo II}

LA MINERÍA EN EL NORTE DE PERÚ, 1798

\begin{tabular}{lccc} 
Partido & $\begin{array}{c}\text { Minas de } \\
\text { Plata } \\
\text { Trabajadas }\end{array}$ & $\begin{array}{c}\text { Minas de } \\
\text { Plata } \\
\text { Abandonadas }\end{array}$ \\
\hline Hualgayoc & 86 & 52 & 349 \\
Pataz & 40 & 18 & 12 \\
Guamachuco & 23 & 14 & 5
\end{tabular}

Fuente: AGI/AL731: 11. 